\title{
Bilateral inferior renal polar arteries with a high origin from the abdominal aorta
}

\author{
Y. Cho' ${ }^{1}$, S.-P. Yoon ${ }^{2,3}$ \\ ${ }^{1}$ Medical Course, Jeju National University School of Medicine, Jeju, Republic of Korea \\ 2Department of Anatomy, Jeju National University School of Medicine, Jeju, Republic of Korea \\ 3Institute for Medical Science, Jeju National University, Jeju, Republic of Korea
}

[Received: 14 February 2020; Accepted: 30 March 2020]

\begin{abstract}
Bilateral multiple renal arteries are not-so-rare variations. However, inferior renal polar arteries with a high origin from the abdominal aorta have rarely been reported. We found bilateral inferior renal polar arteries with a high origin from the abdominal aorta in an 84-year-old Korean female cadaver. Two right and three left renal arteries were seen with the lowest as the main renal artery bilaterally. The highest artery crossed the main renal artery and penetrated into the inferior pole of the kidney, respectively. After dissection, each inferior polar artery could be classified as the inferior segmental branch. A further understanding on its embryogenesis might be important since variations in renal arteries are of particular interest to clinicians as well as anatomists. (Folia Morohol 2020; 80, 1: 215-218)
\end{abstract}

Key words: multiple renal arteries, inferior renal polar artery, inferior segmental branches, anatomical variation, cadaver

\section{INTRODUCTION}

The renal vascular system is extensive and has significant variability, and detailed anatomical knowledge of renovascular varieties is important for clinical and radiologic procedures. The reported incidence of multiple renal arteries is approximately $20 \%$ and varies with ethnicity ranging from $4 \%$ in a Malaysian population to $61.5 \%$ in a Brazilian population [8]. The frequency is lowest in eastern and southern Asia (from $4 \%$ to $18.4 \%$ ), reported to be $13.0 \%$ in Korean. Double and triple renal arteries have been reported, with respective incidences of $18.7 \%$ and $3.0 \%$ [18], $17.4 \%$ and $0.9 \%$ [10], and $19.7 \%$ and $3.6 \%$ [19]. The incidence of bilaterality was much lower, reported in approximately one-fifth of multiple renal arteries [14].

Among these variations, the inferior renal polar arteries usually arise from the aorta or the renal artery, and much less frequently from a suprarenal, common iliac, or superior mesenteric artery [1].
The incidence of inferior renal polar arteries at an extrahilar level originating in the abdominal aorta varies between $0.6 \%$ (71/1237) [1] and $9.7 \%$ (24/250) [19]. Because the metanephros receives more new cranial branches from vessels close to it during ascent while the former lower branches are degenerated [7], incomplete degeneration of the former lower branches leads to the presence of the inferior renal polar artery below the renal artery. Therefore, the inferior renal polar arteries showing upward course have been implicated as an etiological factor in a form of hydronephrosis surgically correctable [1].

The inferior renal polar arteries with a high origin from the abdominal aorta may cross the lower renal arteries to supply the inferior pole of the kidney, which has rarely been reported to date $[2,13,16]$. Herein, we presented a case of bilateral inferior renal polar arteries originating from a high aortic position and discussed its embryological significance. 
Table 1. Morphologic parameters of the bilateral multiple renal arteries. Renal segments classified into superior, anterior superior, anterior inferior, inferior, and posterior according to a previous report [19]

\begin{tabular}{|c|c|c|c|c|}
\hline Variables & $\begin{array}{l}\text { Distance from the bifurcation } \\
\text { of the abdominal aorta [mm] }\end{array}$ & $\begin{array}{l}\text { Vertebrae level } \\
\text { at origin }\end{array}$ & $\begin{array}{l}\text { External diameter } \\
{[\mathrm{mm}]}\end{array}$ & Segmental distribution \\
\hline \multicolumn{5}{|l|}{ Right } \\
\hline R1 & 95 & $\begin{array}{l}\text { Intervertebral space } \\
\text { between LV 1-2 }\end{array}$ & 3 & Inferior \\
\hline $\mathrm{R} 2$ (main) & 91 & Upper half of LV 2 body & 7 & Apical; anterior superior; anterior inferior; posterior \\
\hline \multicolumn{5}{|l|}{ Left } \\
\hline L1 & 101 & $\begin{array}{l}\text { Intervertebral space } \\
\text { between LV 1-2 }\end{array}$ & 4 & Apical; anterior inferior; inferior \\
\hline L2 & 97 & $\begin{array}{l}\text { Intervertebral space } \\
\text { between LV 1-2 }\end{array}$ & 3 & Anterior superior; anterior inferior \\
\hline L3 (main) & 89 & Upper half of LV 2 body & 5 & Apical; posterior \\
\hline
\end{tabular}

LV - lumbar vertebrae
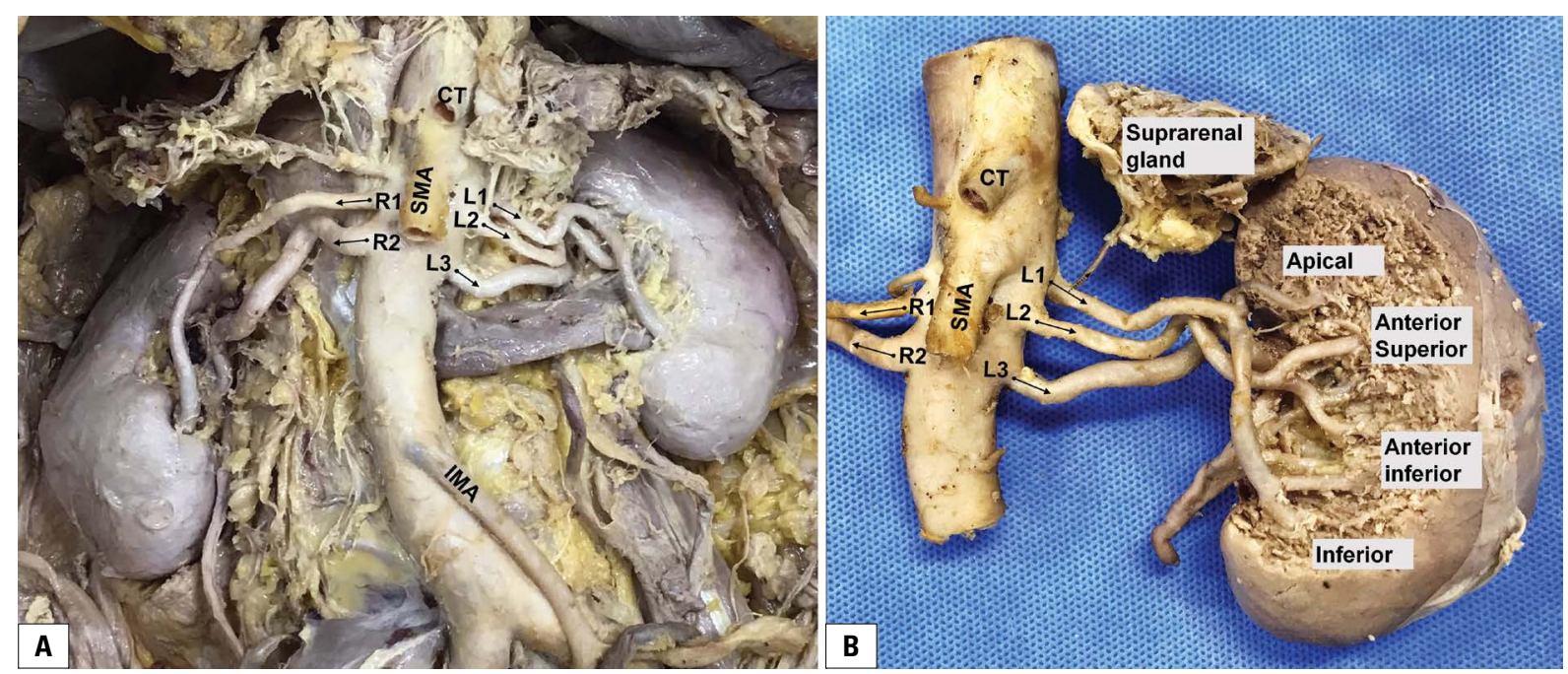

Figure 1. Photographs of bilateral inferior renal polar arteries before $(\mathbf{A})$ and after $(\mathbf{B})$ dissection to clarify the segmental distribution. The multiple renal arteries were designated R1 to R2 from the highest to the lowest on the right side and, similarly, L1 to L3 on the left side. The highest artery (R1 and L1) arose from above the main renal artery (R2 and L3), crossed it, and entered the inferior pole of the kidneys, respectively. Dashed arrow — left suprarenal artery; CT — coeliac trunk; IMA — inferior mesenteric artery; SMA — superior mesenteric artery.

\section{CASE REPORT}

During routine educational dissection, we found a rare variation of bilateral inferior renal polar arteries (Fig. 1) in an 84-year-old Korean female cadaver, whose cause of death was 'cerebral infarction'.

The renal arteries were designated R1 to R2 from the highest to the lowest on the right side and, similarly, L1 to L3 on the left side, in which the lowest was the main renal artery bilaterally. We analysed the distance from the bifurcation of the abdominal aorta, the vertebral level at the origin, the external diameter, the segmental distribution, and other characteristics of each renal artery (Table 1).
On the right side (Fig. 1A), two renal arteries arose from the anterolateral aspect of the abdominal aorta. The superior additional artery (R1) arose from above the main renal artery (R2) and crossed the main renal artery anteriorly into the inferior pole of the right kidney.

On the left side (Fig. 1A), three renal arteries arose from the abdominal aorta. The superior additional artery (L1) arose from the posterolateral aspect of the abdominal aorta just below the superior mesenteric artery, and ran forward the main renal artery (L3), then divided and entered the superior and inferior pole of the left kidney, respectively. The left suprarenal 
artery arose from L1 (Fig. 1B). The middle additional artery (L2) arose from the anterolateral aspect of the abdominal aorta just below the L1, ran forward the main renal artery, and entered the kidney through the hilum below the main renal artery.

\section{DISCUSSION}

The inferior segmental artery variations of the kidney are subdivided into four types based on their origin: I - from the anterior division of the renal artery; II - from the posterior division of the renal artery, III - from the renal artery directly, and IV from the aorta. The incidence of the inferior segmental branch arising from the aorta was approximately $2.2 \%(10 / 459)$ [3], in which most of the inferior segmental branches arose below the renal artery from the aorta. Meanwhile, the incidence of the inferior segmental branches detached from the superior renal artery was $1.6 \%(4 / 250)$ [19]. However, the authors did not mention whether the superior renal artery directly originated from the aorta or not. Only a few reports have been published on the inferior renal polar arteries with a high origin from the abdominal aorta $[2,13,16]$. The reported inferior renal polar arteries with a high origin from the abdominal aorta were right-sided, arose above the main renal artery from the aorta, and entered just below the renal hilum, but clear explanations were lacking. The present case, the bilateral inferior segmental branch from the inferior renal polar arteries with a high origin from the abdominal aorta, might be the first report. A very similar case was reported in bilateral ectopic kidney in the pelvic cavity [7].

Nine pairs of arteries, the cranial (the $1^{\text {st }}$ and the $2^{\text {nd }}$ pair), middle (the $3^{\text {rd }}$ to the $5^{\text {th }}$ pair), and the caudal (the $6^{\text {th }}$ to the $9^{\text {th }}$ pair), form a vascular network from the lateral aorta, the so-called rete arteriosum urogenitale between $6^{\text {th }}$ cervical and $3^{\text {rd }}$ lumbar vertebrae, and supply the mesonephros, metanephros, gonads, and the suprarenal glands [5]. The differing origins and/or additional numbers of renal arteries around the renal hilum are usually explained by this 'ladder theory'. Insufficient degeneration of mesonephric arteries leads to the presence of more than one renal artery, with or without different origins. We agree with the previous report on the bilateral multiple renal arteries, and attempted to suggest a feasible explanation for the present case since the reason why the inferior renal polar arteries develop with a high origin from the abdominal aorta is not known.
The existence of the inferior renal polar arteries with a high origin from the abdominal aorta could be explained by the persistence of a mesonephric artery from the cranial part with a longer oblique course to reach the lower pole of the kidneys as suggested in the case of high-positioned gonadal artery [4]. As in the high-positioned gonadal artery, an extremely high-positioned inferior renal polar artery was also reported with a thoracic origin at the lower thoracic vertebrae $[6,15]$. Compared to normal renal arteries, the ectopic renal arteries arose more posteriorly or posterolaterally in origin from the aorta [7]. In the present case, $\mathrm{L} 1$ arose from the posterolateral aspect of the aorta and supplied the left kidney as the apical, anterior inferior and inferior segments, which might reinforce the previous hypotheses $[4,7]$.

Due to the very complex embryogenesis of the kidneys $[8,9]$, renal vascularisation variants are not uncommon, which is primarily important in surgery, nephrology, and radiology. In any surgical and interventional procedures, including renal transplants, aneursymorraphy, and other vascular reconstructions, unawareness of the presence of multiple renal arteries may result in a fatal outcome. The inferior renal polar artery with a high origin from the abdominal aorta showed a narrow calibre which has suggested as an etiological factor of renovascular hypertension [2]. Although the mean renal artery diameter found in cadavers casted with synthetic resin $(4.87 \mathrm{~mm})$ was slightly less than that reported in angiographic studies $(5.9 \mathrm{~mm})$ [17], the dimeter of multiple renal arteries was significantly smaller than when a single renal artery was present [11] and the presence of a supernumerary renal artery should be predicted when the main renal artery has a luminal diameter less than $4.15 \mathrm{~mm}$ in a cadaveric study [17]. Recently, the sum of the luminal areas of smaller, additional renal vessels needs to be equal to or a little higher than that of a single renal artery to compensate for based on the renal-aortic ratio [12]. In the present case, the right main renal artery was thicker than the left one, and more additional arteries on left side were expected, as suggested.

\section{CONCLUSIONS}

Taken together, we clearly showed bilateral inferior renal polar arteries with a high origin from the abdominal aorta for the first time based on embryological explanation. The renal artery presents a variety of spectra in morphological representations of num- 
bers, length, diameter, and branching level, which is extremely important as it enables efficient clinical interventions and reduces the risk of complications. Because the renal artery is an end artery, a deeper understanding on the renovascular development is important to clinicians as well as anatomists.

\section{Acknowledgements}

This research was supported by the 2020 scientific promotion program funded by Jeju National University.

\section{REFERENCES}

1. Bergman RA, Afifi AK, Miyauchi R. Illustrated encyclopedia of Human Anatomic Variation: Opus II: Cardiovascular System: Arteries: Abdomen: Variations in Branches of Celiac Trunk. https://www.anatomyatlases.org/AnatomicVariants/Cardiovascular/Text/Arteries/RenalInferiorPolar. shtml (Cited Jan 28, 2020).

2. Chan PL, Tan FH. Renin dependent hypertension caused by accessory renal arteries. Clin Hypertens. 2018; 24: 15, doi: 10.1186/s40885-018-0100-x, indexed in Pubmed: 30410790 .

3. Chandragirish S, Nanjaiah CM, Shirur SY, et al. Study on variations of inferior segmental branch of renal artery. Int J Anat Res. 2014; 2(4): 716-719, doi: 10.16965/ ijar.2014.534.

4. Ciçekcibaşi $A E$, Salbacak $A$, Seker $M$, et al. The origin of gonadal arteries in human fetuses: anatomical variations. Ann Anat. 2002; 184(3): 275-279, doi: 10.1016/S09409602(02)80126-1, indexed in Pubmed: 12056759.

5. Felix W. The development of the urogenital organs. In: Keibel F, Mall FP eds. Manual of human embryology. J.B. Lippincott Company, Philadelphia 1912: 752-880.

6. Gadabanahalli $K$, Bhat V. Thoracic origin of single right renal artery: some interesting facets. Int J Angiol. 2017; 26(4): 264-266, doi: 10.1055/s-0037-1604328, indexed in Pubmed: 29142495.

7. Gokalp G, Hakyemez B, Erdogan C. Vascular anomaly in bilateral ectopic kidney: a case report. Cases J. 2010; 3: 5, doi: 10.1186/1757-1626-3-5, indexed in Pubmed: 20076808.

8. Gulas E, Wysiadecki G, Cecot T, et al. Accessory (multiple) renal arteries - Differences in frequency according to population, visualizing techniques and stage of morpho- logical development. Vascular. 2016; 24(5): 531-537, doi: 10.1177/1708538116631223, indexed in Pubmed: 26945775.

9. Gulas E, Wysiadecki G, Szymański J, et al. Morphological and clinical aspects of the occurrence of accessory (multiple) renal arteries. Arch Med Sci. 2018; 14(2): 442-453, doi: 10.5114/aoms.2015.55203, indexed in Pubmed: 29593819.

10. Khamanarong $K$, Prachaney $P$, Utraravichien $A$, et al. Anatomy of renal arterial supply. Clin Anat. 2004; 17(4): 334-336, doi: 10.1002/ca.10236, indexed in Pubmed: 15108340.

11. Majos M, Stefańczyk L, Szemraj-Rogucka Z, et al. Does the type of renal artery anatomic variant determine the diameter of the main vessel supplying a kidney? A study based on CT data with a particular focus on the presence of multiple renal arteries. Surg Radiol Anat. 2018; 40(4): 381-388, doi: 10.1007/s00276-017-1930-z, indexed in Pubmed: 28980056.

12. Majos M, Polguj M, Stefańczyk L, et al. Renal-aortic ratio as an objective measure of renal artery diameter a computed tomography angiography study. BMC Cardiovasc Disord. 2019; 19(1): 181, doi: 10.1186/s12872-019-1163-7, indexed in Pubmed: 31362712.

13. Mantraratnam PP, Bhattam NR. A study on accessory renal arteries in cadavers and its clinical correlation. Int J Health Sci Res. 2016; 6: 148-150.

14. Ozkan U, Oğuzkurt L, Tercan F, et al. Renal artery origins and variations: angiographic evaluation of 855 consecutive patients. Diagn Interv Radiol. 2006; 12(4): 183-186, indexed in Pubmed: 17160802.

15. Patel K, Gandhi S, Modi P. Unusual origin of right renal artery: a report of two cases. J Clin Diagn Res. 2016; 10(5): TJ03-TJ04, doi: 10.7860/JCDR/2016/18428.7823, indexed in Pubmed: 27437328.

16. Ramesh Rao T, Shetty P, Rao S. Unusual course of accessory renal artery and its clinical significance: a case report. Int J Anat Var. 2011; 4: 197-199.

17. Saldarriaga B, Pinto S, Ballesteros L. Morphological expression of the renal artery: a direct anatomical study in a colombian half-caste population. Int J Morphol. 2008; 26(1), doi: 10.4067/s0717-95022008000100005.

18. Vilhova I, Kryvko YY, Maciejewski R. The radioanatomical research of plural renal arteries. Folia Morphol. 2001; 60(4): 337-341, indexed in Pubmed: 11770346.

19. Zăhoi DE, Sztika D, Dăescu E. Morphological variability of arterial sources of the renal polar parenchyma and its clinical importance. Rom J Morphol Embryol. 2015; 56(4): 1403-1409, indexed in Pubmed: 26743287. 